\title{
Willingness to pay for ovulation induction treatment in case of WHO II anovulation: a study using the contingent valuation method
}

This article was published in the following Dove Press journal:

Patient Preference and Adherence

26 September 2014

Number of times this article has been viewed

\author{
Thomas G Poder' \\ Jie $\mathrm{He}^{2}$ \\ Catherine Simard ${ }^{3}$ \\ Jean-Charles Pasquier ${ }^{4}$ \\ 'UETMIS and CRCHUS, CHUS, \\ Sherbrooke, QC, Canada; \\ ${ }^{2}$ Department of Economics, GREDI, \\ University of Sherbrooke, QC, \\ Canada; ${ }^{3}$ Department of Obstetrics \\ and Gynecology, $\mathrm{CH}$ of Chicoutimi, \\ affiliated to CHUS, QC, Canada; \\ ${ }^{4}$ Department of Obstetrics and \\ Gynecology, CHUS, Sherbrooke, \\ QC, Canada
}

Objective: To measure the willingness to pay (WTP) of women aged 18-45 years to receive drug treatment for ovulation induction (ie, the social value of normal cycles of ovulation for a woman of childbearing age) in order to feed the debate about the funding of fertility cares.

Setting: An anonymous questionnaire was used over the general population of Quebec.

Participants: A total of 136 subjects were recruited in three medical clinics, and 191 subjects through an online questionnaire.

Method: The questionnaire consisted of three parts: introduction to the problematic, socioeconomic data collection to determine factors influencing the formation of WTP, and a WTP question using the simple bid price dichotomous choice elicitation technique. The econometric estimation method is based on the "random utility theory." Each subject responding to our questionnaire could express her uncertainty about the answer to our WTP question by choosing the answer "I do not know."

Outcome measure: The WTP in Canadian dollars of women aged 18-45 years to receive drug treatment for ovulation induction.

Results: Results are positive and indicate an average WTP exceeding 4,800 CAD, which is much more than the drug treatment cost. There is no evidence of sample frame bias or avidity bias across the two survey modes that cannot be controlled in econometric estimates.

Conclusion: Medical treatment for ovulation induction is highly socially desirable in Quebec.

Keywords: WTP, fertility, drug therapy

\section{Introduction}

According to Chandra et $\mathrm{al}^{1}$ approximately $11 \%-27 \%$ of women of reproductive age experience infertility problems; the diagnosis of infertility being formulated after 1 year of unprotected sex that did not lead to pregnancy. ${ }^{2}$

Ovulation disorders are a very common cause of infertility among women. Among these disorders, World Health Organization group 2 (WHO II) anovulation is the most common, and up to $40 \%$ of infertile women are coping with it. ${ }^{3,4}$ The normal ovarian cycle is so complex that even the smallest abnormalities may disrupt the cycle and prevent ovulation. However, modern treatments offer very good chances of eventually obtaining a pregnancy in these women.

For most women, infertility is more than just a physical problem. Establishing a diagnosis of infertility often has a significant social and emotional impact. Infertile women frequently experience a feeling of anger and frustration, a feeling of loss of control, isolation vis-à-vis friends and family, depression, and pain. These feelings can become overwhelming at times and it follows inexorably the emergence of stress.
Correspondence: Thomas G Poder Unité ETMIS, Hôpital Hôtel-Dieu, CHU de Sherbrooke, 580, rue Bowen Sud, Sherbrooke, QC JIG 2E8, Canada $\mathrm{Fax}+\mathrm{I} 8198293247$

Email tpoder.chus@ssss.gouv.qc.ca 
During the last two decades, the number of new data discovered on infertility has exploded, and considerable progress has been made regarding treatment. Among the therapeutic advances, we must note the progress on hormonal therapies - over $80 \%$ of infertile women treated for WHO II anovulation and without anatomic disorders are treated successfully with fertility drugs. For example, clomiphene citrate is easy to use and results in ovulation in a majority of patients with WHO II anovulation $(60 \%-90 \%))^{5}$

However, if medical effectiveness of the treatment is a major element when deciding which treatment option to pursue in infertile women, cost also plays an important role. In this setting, cost-effectiveness ratios are of major concern when government decides which intervention or drug to reimburse or not. From an economic point of view, the financial constraints imposed on society urge us to understand the real value accorded by people, and particularly women, for such treatments. In other words, are these treatments worthy? What is the value given by women to have normal cycles of ovulation and to avoid suffering from the social and emotional impact of anovulation? Is this value higher than the cost of the intervention?

The "benefit" provided by a medication to trigger ovulation in infertile females can be measured by the proportion of women having ovulation following such treatment. However, this benefit is not monetarily valued, which involves a problem of cost comparison of treatment with its "benefit." For a cost-benefit analysis, one must know the monetary value that individuals attach to perform ovulation following treatment. One way to obtain such a monetary value is to estimate the willingness to pay (WTP) of individuals to benefit from this treatment, given the likelihood of success of this treatment and the prevalence of WHO II anovulation in the female population of childbearing age.

To measure the WTP of women to receive a drug treatment for ovulation induction, we conducted a contingent valuation survey. This study is one of only two that has studied the WTP for a medical treatment for ovulation induction. Different from the first study published, ${ }^{6}$ we measured WTP for a drug treatment with a given probability of success and not WTP for controlled ovarian stimulation (COS). In addition, our study considers uncertainty in a respondent's answer, which is rarely done in contingent valuation surveys. We hope this study will help in better understanding how women value medical treatment for ovulation induction and to consider it in the debate about funding in fertility care. Indeed, in Quebec, the decision of whether to reimburse fertility care to all couples was hotly discussed after its adoption in 2010 and is now challenged by the new government. The debate was mainly about the public funding of this expensive health care service in a context of a lack of resources for other health care considered more essential.

\section{Objectives}

The first objective of this study was to measure the WTP of women aged 18-45 years to receive a drug treatment for ovulation induction in cases where they will be affected by anovulation. The second objective was to test whether there are biases that can arise due to differences in survey mode. Indeed, there is no clear indication in the WTP literature as regard to the best survey mode to use, and to choose a specific survey mode could have biased our results.

\section{Contingent valuation method and study design}

The contingent valuation model is a very popular method in environmental studies to provide valuation for nonmarket services or goods, and its methodological improvement has been rapid over the last two decades..$^{7-9}$ In recent years, contingent valuation has been increasingly applied to topics in health economics. ${ }^{10-12}$

In this paper, we follow the recommendation made by the National Oceanic and Atmospheric Administration (NOAA) ${ }^{13}$ The NOAA panel concluded that contingent valuation methods can generate useful information and issued the following recommendations to maximize the reliability of contingent valuation estimates: 1) use of a probability sample; 2) using face-to-face or telephone interviews but not mail surveys; 3 ) measuring WTP rather than willingness to accept; 4) pretesting of the contingent valuation questionnaire; 5) phrasing contingent valuation questions in the form of hypothetical situation in which respondents are told how much they would have to pay if the situation arose and are then asked to cast a simple yes or no; 6) providing a "would not vote" or a "I do not know" option in addition to the "yes" and "no" options on the WTP question; 7) breaking down WTP by a variety of respondent characteristics such as income, age, interest, and attitudes; and 8) reminding respondents of their actual budget constraint when considering their WTP. With the exception of the second point, the survey questions designed for this paper adhered to each of these recommendations. On the second point, more recent studies have reported specific bias in each recruitment mode and have not concluded to a superiority of one mode over another. ${ }^{14,15}$

This paper used the simple bid contingent valuation model in which survey respondents are asked to choose 
between three options of answers which are yes, do not know, or not to illustrate their WTP for a drug treatment in case they will face ovulation disorders. ${ }^{7}$ In this study, seven price levels are proposed: 200, 500, 1,000, 1,500, 2,000, 3,000, and 5,000 CAD. The simple bid method is generally preferred to asking an open-ended question about WTP. ${ }^{16}$ For example, researchers found that people commonly gave "protest answers" to open-ended questions, responding with zeros or extremely high values. ${ }^{17}$ Another problem is that people may also give a strategic answer and thus an amount over- or underestimated. Asking a simple yes/no question eases the burden on the respondent, therefore decreasing the number of protest and strategic answers.

In addition, the "I do not know" option allows protest and uncertain answers to be submitted without introducing bias in estimates of WTP. Another consideration pushing us to add the "I do not know" option is that, given the WTP question is a hypothetical question, it is reasonable to wonder whether respondents do not give random answers to complete the questionnaire more quickly. According to Arrow et $\mathrm{al}^{13}$ and Whitehead, ${ }^{18}$ introducing a response option "Do not know" or "Do not vote" allows respondents to quickly fill in their questionnaire without generating a nonsense WTP answer.

In order to examine mode effects, two modes of recruitment have been performed: an online survey and a paper survey. For the online survey, a survey sampling company provided a random selection of its panelists, who were then invited to participate in the study. The paper survey has been distributed at convenience in three clinics (one Family Medicine Group, one dermatology clinic, and one gynecology clinic; the last two sharing the same waiting room for patients). All eligible patients in the waiting room were invited to participate. The paper survey's patient recruitment was done by the secretaries of these clinics, and patients completed the questionnaire by themselves. With regard to survey modes, three major biases were considered: sample frame bias, avidity bias, and nonresponse bias. Sample frame bias refers to the population that is used to draw a sample. If the characteristics of these people differ systematically from the rest of the population then this could bias results. Avidity bias refers to the notion that those with a greater interest in the survey topic are more likely to provide a "Yes" answer to the WTP question. Finally, nonresponse bias refers to the composition of the sample that chose to complete the survey (ie, we do not know the characteristic of the nonrespondent), which raises the problem of representativeness of the sample.
The study has been approved by the ethics committee of our hospital. The only criterion for inclusion in this study was to be a female Quebec resident aged 18-45 years. Each woman solicited was informed of the purpose of the research through an explanatory letter. Surveys took place between January 2, 2009 and July 31, 2010.

Each questionnaire consists of three parts. The first component allows presenting the current state of infertility and ovulation disorders in the female population, its psychosocial consequences, and the potential benefits of drug treatments. The second component includes demographic and socioeconomic questions in order to establish the profile of the respondents and to better determine the factors influencing the formation of their WTP. The third component corresponds to our question of WTP. In the WTP section, women were asked to imagine suffering from ovulation disorders and being at the point of consumption (ex-post question). The WTP bids represented a "once only" amount to be paid.

To test "scope effect" (ie, different values given for different scopes), we split the hypothetical effect of our scenario in two different rates of success with fertility drugs (60\% vs $80 \%$ ). In addition, to prevent any "budget constraint effect," the respondent was reminded, before the WTP question, of the following sentence:

Next question is hypothetical and there are no correct or false answers. Before answering, please take the time to consider that to pay for a drug treatment for ovulation induction leads to a reduction in the amount of money available to pay for other goods and services (eg, hobbies, clothes, travelling, etc.).

Finally, the distribution of the questionnaires with different rates of success and different bid prices was carried out randomly. Table S1 (Supplementary material) shows examples of contingent valuation questions.

\section{Econometric methodology}

The typical theoretical framework used for the analysis of closed-ended contingent valuation method is based on the random utility model originally formulated by McFadden ${ }^{19}$ and extended by Hanemann. ${ }^{20}$ Essentially, the construction employs a dichotomous Probit model in which the independent variables explain the probability that a respondent $i$ will say "Yes" to the WTP question at a specified price $B i d_{i}$ that the surveyor proposed to her. More specifically, the random utility model formulates this process as the probability for the WTP of a respondent $i$ for the drug to be larger than the price proposed to her, noted as Bid ${ }_{i}$. This can be written as Equation 1. 


$$
\operatorname{Prob}\left(\text { vote }_{i}=Y E S\right)=\operatorname{Prob}\left(\text { WTP }_{i}>\text { Bid }_{i}\right)
$$

Although the WTP of the respondent is a non-observable latent value that cannot be directly measured by our survey, we can use a vector of respondent's socioeconomic characteristics $X$ to explain it in our model, this can be written as Equation 2, where $\varepsilon_{i}$ is the random error following the normal distribution.

$$
W T P_{i}=X_{i}^{\prime} \beta+\varepsilon_{i}, \varepsilon_{i} \sim N\left(0, \sigma^{2}\right)
$$

Replacing Equation 2 into Equation 1 gives us:

$$
\begin{aligned}
\operatorname{Prob}\left(\text { vote }_{i}=Y E S\right) & =\operatorname{Prob}\left(X_{i}{ }^{\prime} \beta+\varepsilon_{i}>\text { Bid }_{i}\right) \\
& =\operatorname{Prob}\left(\frac{\varepsilon_{i}}{\sigma}>\frac{B_{i}-X_{i}{ }^{\prime} \beta}{\sigma}\right) \\
& =\operatorname{Prob}\left(\frac{X_{i}{ }^{\prime} \beta-B_{i d_{i}}}{\sigma}\right)
\end{aligned}
$$

Equation 3 is a typical Probit model in which we expect the independent variables $X_{\mathrm{i}}^{\prime}$ and $\mathrm{Bid}_{i}$ to explain the probability for the respondent $i$ to accept the drug. Logically, the negative coefficient $(-1 / \sigma)$ before the Bid corresponds to our intuition that the higher the Bid, the lower will be the probability to accept the drug. For the socioeconomic variables $X$, their impact on WTP can be directly interpreted from estimation results, except that their absolute impact of WTP is scaled by $(1 / \sigma)$. The mean WTP of the surveyed sample is therefore:

$$
\overline{W T P_{i}}=\overline{X_{i}}{ }^{\prime} \hat{\beta} \text { since } \varepsilon_{i} \sim N\left(0, \sigma^{2}\right)
$$

In this study, we also consider the possibility for respondents to provide a "Do not know" answer. To consider this last point, the Probit model we used was split into three econometric estimations. Firstly, we consider all "Do not know" answers as positive answers (ie, respondents seem to say "Yes"), which gives us an upper bound for WTP. Secondly, we consider all "Do not know" answers as negative answers (ie, respondents seem to say "No"), which gives us a lower bound for WTP. Finally, we drop all "Do not know" answers (ie, respondents really do not know), which gives us an intermediate value for WTP.

In order to examine mode effects, we firstly test whether or not samples differ in terms of demographic and attitudinal characteristics. To do so, independent $t$-tests were used to compare mean scores. The statistical significance level for each test was set at $P<0.10$ on the basis of a two-tailed test. If significant differences appear, it could indicate the presence of a bias. Secondly, the existence of bias is also tested in Probit estimates by introducing a dummy "Paper" with value 1 if the survey mode is paper and value 0 if the survey mode is electronic.

\section{Results}

Surveys allowed collecting 362 questionnaires from the general population, including 334 completed. Seven completed questionnaires were excluded because respondents were older than 45 years. The total number of observations available for analysis is thus 327 . Variable descriptions are given in Table 1 and descriptive statistics in Table 2.

In Table 2, we compared each variable across modes. As regard to demographic and socioeconomic variables, respondents to the paper mode survey were significantly younger, with a lower income per capita, without a spouse, and with fewer children, possibly indicating a sample frame bias. Considering these different points with the official statistics, it is possible to consider that the paper mode is slightly more representative than the Internet mode in our study. With regard to attitudinal variables, the major difference is provided by the percentage of respondents having already experienced ovulation disorders (higher percentage in the paper survey). This last element allows us to consider a potential avidity bias with the paper mode. However, with regard to other attitudinal variables (ie, subjects with a possible greater interest in the topic), differences do not follow a systematic pattern that would suggest avidity bias.

Using three different Probit, and controlling by all demographic, socioeconomic, and attitudinal variables mentioned earlier, we can observe in Table 3 that the dummy associated with the paper mode is not significant. Consequently, in this survey, the survey mode does not seem to have an impact on the WTP for a drug treatment in the case of women aged 18-45. As a consequence, our presumption of sample frame bias in Table 2 is not confirmed by our results in Table 3. In fact, the sample frame bias related to the socioeconomic and demographic characteristics collected in our survey is totally eliminated in Probit estimates, and it seems that unobservable characteristics associated to a sample frame bias are not associated to the dummy "paper". This finding is interesting as much as it indicates that we can probably use these two modes alternatively when controlling by socioeconomic and demographic characteristics of the respondents. Another result of interest is the seeming absence 
Table I Variable descriptions

\begin{tabular}{|c|c|c|c|}
\hline Variable & Description & & \\
\hline Bid price & Price offered between 200 and 5,000 CAD & Winter & Survey completed in winter \\
\hline Age & Age of respondent in years & Spring & Survey completed in spring \\
\hline Income & Gross income per capita in CAD & Autumn & Survey completed in autumn \\
\hline Employed & Respondent is employed & Stress & Job is stressful: yes $=1 ;$ no $=0$ \\
\hline Child & Respondent have one child or more & Pregnant & Respondent is pregnant \\
\hline Child $\times$ Infertility & $\begin{array}{l}\text { Respondent having a child has already had } \\
\text { infertility problems }\end{array}$ & Get child & $\begin{array}{l}\text { Having child is part of the } \\
\text { most four important things } \\
\text { in life }\end{array}$ \\
\hline Secondary & Respondent has a secondary level or less & Desire child & $\begin{array}{l}\text { Desire to have a child in } \\
\text { years to come }\end{array}$ \\
\hline High school & Respondent has a high school level & Ovulation disorders & $\begin{array}{l}\text { Respondent has already } \\
\text { experienced ovulation } \\
\text { disorders }\end{array}$ \\
\hline University & Respondent has a university level & Infertility family & $\begin{array}{l}\text { Member of the } \\
\text { respondent's family has had } \\
\text { problems with infertility }\end{array}$ \\
\hline Alone & $\begin{array}{l}\text { Respondent has no spouse }=\mathrm{l} \text {; } \\
\text { otherwise }=0\end{array}$ & FMG & $\begin{array}{l}\text { Respondent answered in a } \\
\text { Family Medicine Group }\end{array}$ \\
\hline Smoker & Respondent is a smoker & Internet & $\begin{array}{l}\text { Internet survey }=1 \\
\text { otherwise }=0\end{array}$ \\
\hline Health & Very good health $=\mathrm{I}$; otherwise $=0$ & Success 60 & $\begin{array}{l}\text { Rate of success with fertility } \\
\text { drug is } 60 \%\end{array}$ \\
\hline Year & Year $2010=I ;$ year $2009=0$ & Success 80 & $\begin{array}{l}\text { Rate of success with fertility } \\
\text { drug is } 80 \%\end{array}$ \\
\hline
\end{tabular}

Abbreviations: CAD, Canadian dollars; FMG, Family Medicine Group.

Table 2 Descriptive statistics (mean values) according to the survey mode

\begin{tabular}{|c|c|c|c|}
\hline Variable & Paper & Internet & Official statistics \\
\hline \multicolumn{4}{|l|}{ Demographic and } \\
\hline \multicolumn{4}{|l|}{ socioeconomic variables } \\
\hline Age, years & $30.38^{*}$ & $32.25^{*}$ & 33.6 (StatCan, 2006) \\
\hline Income per capita & $33,866 *$ & $4 I, 368 *$ & 35,400 (StatCan, 2008) \\
\hline Employed, \% & $72.06 *$ & $80.10 *$ & \\
\hline Child, \% & $47.80 *$ & $60.73 *$ & \\
\hline Secondary, \% & 16.91 & $|5.7|$ & 47.3 (StatCan, 2006) \\
\hline High school, \% & 36.02 & 37.17 & 31.3 (StatCan, 2006) \\
\hline University, \% & 47.06 & 47.12 & 21.4 (StatCan, 2006) \\
\hline Alone & $37.50^{*}$ & $23.04 *$ & 38 (StatCan, 2006) \\
\hline \multicolumn{4}{|l|}{ Attitudinal variables } \\
\hline Smoker, \% & 16.91 & 19.37 & 27 (StatCan, 2007) \\
\hline Health, \% & 30.88 & 30.37 & \\
\hline Stress & 86.76 & 91.10 & \\
\hline Pregnant & 8.09 & 5.76 & \\
\hline Get child & $73.53^{*}$ & $63.87 *$ & \\
\hline Desire child & $65.44^{*}$ & $50.79 *$ & \\
\hline Ovulation disorders & $7.35^{*}$ & $3.66 *$ & \\
\hline Infertility family & 20.59 & 20.94 & \\
\hline \multicolumn{4}{|l|}{ Structure of the survey } \\
\hline Year $(2010=I ; 2009=0)$ & 18.38 & 15.18 & \\
\hline Winter & $27.94 *$ & $49.74 *$ & \\
\hline Spring & $35.29 *$ & $9.95^{*}$ & \\
\hline Autumn & $16.18^{*}$ & $0.00 *$ & \\
\hline Success 60 & $44.85^{*}$ & $59.69 *$ & \\
\hline Success 80 & $55.15^{*}$ & $40.31 *$ & \\
\hline Number of observations & 136 & 191 & \\
\hline
\end{tabular}

Notes: *The variable is significantly different as compared to the other mode at a threshold of $10 \%$ or less. 
Table 3 Probit estimations of WTP (dependent variable is the answer to the WTP question: Yes, No, or Do not know)

\begin{tabular}{|c|c|c|c|}
\hline Variables & DK $=$ Yes & DK $=$ No & DK $=.^{a}$ \\
\hline Bid price, thousand CAD & $-0.256(0.000)$ & $-0.292(0.000)$ & $-0.307(0.000)$ \\
\hline Smoker & $0.125(0.616)$ & $0.209(0.331)$ & $0.214(0.430)$ \\
\hline Age & $-0.005(0.764)$ & $-0.006(0.678)$ & $-0.007(0.694)$ \\
\hline Income, thousand CAD & $0.005(0.237)$ & $\mathbf{0 . 0 0 7}(0.059)$ & $0.007(0.14 I)$ \\
\hline Child & $-0.030(0.905)$ & $-0.205(0.343)$ & $-0.142(0.621)$ \\
\hline Child $\times$ Infertility & $0.136(0.743)$ & $0.102(0.770)$ & $0.163(0.737)$ \\
\hline High school & $-0.58 \mathrm{I}(0.038)$ & $-0.770(0.002)$ & $-0.709(0.017)$ \\
\hline University & $0.050(0.88 \mathrm{I})$ & $-0.276(0.344)$ & $0.008(0.983)$ \\
\hline Paper & $0.186(0.644)$ & $0.074(0.83 \mathrm{I})$ & $0.297(0.483)$ \\
\hline FMG & $0.049(0.906)$ & $0.288(0.427)$ & $0.039(0.930)$ \\
\hline Success 60 & $0.165(0.452)$ & $0.060(0.762)$ & 0.111 (0.649) \\
\hline Health & $0.185(0.373)$ & $0.55 I(0.003)$ & $0.338(0.129)$ \\
\hline Alone & $0.325(0.175)$ & $0.228(0.258)$ & $0.345(0.177)$ \\
\hline Year & $-0.170(0.554)$ & $0.120(0.637)$ & $-0.020(0.948)$ \\
\hline Winter & $-0.232(0.381)$ & $0.013(0.955)$ & $-0.240(0.405)$ \\
\hline Spring & $0.003(0.993)$ & $-0.254(0.320)$ & $-0.167(0.616)$ \\
\hline Autumn & $-0.084(0.870)$ & $-0.158(0.709)$ & $-0.210(0.705)$ \\
\hline Employed & $0.742(0.001)$ & $0.290(0.141)$ & $0.740(0.002)$ \\
\hline Stress & $0.543(0.061)$ & $0.807(0.003)$ & $0.728(0.029)$ \\
\hline Pregnant & $-0.189(0.624)$ & $0.355(0.324)$ & $-0.077(0.852)$ \\
\hline Get child & $0.604(0.004)$ & $0.421(0.025)$ & $0.662(0.005)$ \\
\hline Desire child & $0.409(0.073)$ & $0.101(0.625)$ & $0.335(0.208)$ \\
\hline Ovulation disorders & $-0.367(0.432)$ & $-0.101(0.807)$ & $-0.323(0.548)$ \\
\hline Infertility family & $0.124(0.606)$ & $0.105(0.610)$ & $0.206(0.433)$ \\
\hline Constant & $-0.178(0.791)$ & $-0.239(0.699)$ & $-0.351(0.634)$ \\
\hline$R^{2}$ & 0.218 & 0.199 & 0.266 \\
\hline Number of observations & 327 & 327 & 275 \\
\hline WTP (in CAD) & 6,014 & 3,412 & 4,805 \\
\hline
\end{tabular}

Notes: ${ }^{a}$ Respondents that answered DK were excluded from the estimate. P-values are in parentheses. Significant coefficients at a threshold of I0\% are in bold. Several specification models were performed as regard to infertility variables; no major changes were observed.

Abbreviations: CAD, Canadian dollars; DK, do not know; FMG, Family Medicine Group; WTP, willingness to pay.

of "scope effect" as indicated by the variable "success 60 " whose coefficient is never significant, which is maybe due to the gap between $60 \%$ and $80 \%$ and that could be judged to be insufficient to change respondents' answers.

With regard to the socioeconomic variables, most of them report intuitively logical coefficients. As explained above, while the sign of the coefficient for a variable can be directly used to interpret its impact on WTP, its absolute coefficient value in WTP determination function should be converted from the estimated coefficients by dividing the absolute value of the estimated coefficient by the Bid $_{i}$. Taking the example of the dummy variable Highschool, with a significant negative coefficient in all the three estimation models, this signifies that women having a relatively lower education level (compared with university level) have lower WTP for the drug. Concerning the detailed influence of education level on WTP, we should convert the coefficient of the variable High-school, which is $-\beta_{\text {high-school }} / \beta_{\text {bid }}$, this will give a value of $-0.581 / 0.256=-2.27$, which signifies that all else being equal, a woman having high-school education should have a WTP 2.27 CAD lower than a woman having the reference level of education. The same logic can be applied to the other socioeconomic variables. With regard to income, estimated coefficients are not always significant. Indeed, this variable has the significant expected sign only in the regression where "Do not know" is considered as a "No." To the contrary, some other variables were found to influence WTP in a manner consistent with a priori expectations, therefore providing further support for the internal validity of the technique. This is the case for the bid price proposed, the education level, the stress experienced at work, and the importance in life of having a child. Consistent with our expectations, the bid price and the importance in life of having a child were strongly associated with WTP. More specifically, women experiencing stress at work were more willing to pay for a treatment considering that normal ovulations could help in establishing a better balance in their lives. 
Finally, these results allow us to calculate an average WTP of 4,805 CAD, with a lower bound of 3,412 CAD and an upper bound of 6,014 CAD.

\section{Discussion}

Before our study, there was only one about WTP in the field of ovulation disorders. Specifically, the study of Palumbo et a ${ }^{6}$ was about COS and indicated a mean WTP of 1,442 euros for one cycle. No econometric estimations were performed in this study (ie, WTP was the sum of the responses divided by the number of respondents), and some requirements for contingent valuation study ${ }^{13}$ were not achieved. Three other WTP studies conducted in the field of infertility are about in vitro fertilization (IVF). In the study by Granberg et $\mathrm{al}^{21}$ the mean WTP for having a child was more than $£ 10,000$. As in the study of Palumbo et $\mathrm{al}^{6}$ no econometric estimations were performed, and the formulation of the WTP question was even simpler. In the last two studies we have identified, econometric estimations were used, and more attention has been paid to prevent bias. The one conducted by Neumann and Johannesson ${ }^{22}$ indicated, among 150 respondents who were potential childbearers, an average WTP of 17,730 USD for a $10 \%$ chance at having a child through IVF in the event of infertility. In the studies of Ryan, ${ }^{23,24}$ WTP for one cycle of IVF was about $£ 5,000$. In our study, the main difference with these last three studies is that we measured WTP for normal cycles of ovulation that can lead to having a child and not WTP for directly having a child or for one cycle of IVF.

Compared with these studies, our results for WTP are quite high. Maybe it is because that in the mind of respondents, such a treatment in order to have normal cycles of ovulation has two major advantages: to recover normal cycles of ovulation and to increase the possibility to bear a child. From this perspective, even if we did not give probability of success to get a child in our survey, but probability of success to have normal cycles of ovulation, respondents may have answered with this second point in mind. As a consequence, it would have been of interest to conduce a subsequent qualitative face-to-face survey to investigate this point. Another explanation for this high WTP is maybe related to the cost of some infertility treatments (eg, assisted reproductive techniques), which were abundantly discussed in the media during the conduct of this survey.

Specifically comparing our results of WTP with those of Palumbo et $a l^{6}$ we found values $2-3$ times higher. However, the WTP they calculated was only for one cycle of COS, while we asked respondents to give their WTP to recover normal cycles of ovulation with a probability of success of $80 \%$ or $60 \%$. Considering that women with ovulation disorders generally need to perform several cycles of COS to obtain normal cycles of ovulation, it can be argued that our results are closed to those of Palumbo et al. ${ }^{6}$ With regard to the study of Neumann and Johannesson ${ }^{22}$ about in vitro fertilization, indicating an average WTP of 17,730 USD for a $10 \%$ chance at having a child, we can relate this result with the literature review of Homburg ${ }^{25}$ indicating for clomiphene citrate therapy an ovulation rate of $73 \%$ and a pregnancy rate of $36 \%$, with a theoretical projection of 25 women over 100 who would succeed in delivering a singleton healthy baby. Given the results provided by our study and a deflator of 1.4 between 1994 and 2010 (ie, inflation of 40\%), we can indicate that women are five times less willing to pay for a drug treatment for ovulation induction than for an IVF with a given probability to get a child. However, it is difficult to compare these results given spatial and temporal differences between the two surveys and the fact that in our survey we did not mention a probability to get a child, but a probability to have normal cycles of ovulation.

Another point of interest to mention is the fact that the variable of age has no effect on WTP in our study. Same results were found in the studies of Palumbo et al, ${ }^{6} \mathrm{Ryan},{ }^{23,24}$ and Neumann and Johannesson. ${ }^{22}$ In our study, it may be because we mentioned in the introduction to the survey that the risk of ovulation disorders increases with age, which could explain why older women may want to benefit from such a treatment as much as younger women.

We also found no "scope effect." This result is different from the one obtained by Palumbo et $a{ }^{6}$ where they indicated an additional WTP for a small $1 \%-2 \%$ increase in a successful pregnancy rate from a COS. Such a difference may be explained by the scenario they used, where the focus was mainly on the WTP for a specific COS with a higher gain in probability and other characteristics. Indeed, in our WTP question, we did not compare between two different treatments and only focused on the probability of having normal ovulations. However, if we compare our results with other studies in health having tested a scope effect, it seems that our result is not unusual, ${ }^{26,27}$ particularly when respondents are not directly facing different rates of success, as in our study (ie, probabilities were given in the introduction).

Considering that income has no effect in our study on the WTP of women, it can be argued that the women being interviewed were facing a subject so intimate, so vital for their wellbeing, that their answers were independent of their income. A similar result was found in the study of Palumbo et al. ${ }^{6}$ In addition, it is possible that 
some respondents were aware of the cost of the treatment, which could have introduced an anchor bias and led them not to respond according to their WTP but to the gap between the price proposed and the idea they had about the real price.

During the last two decades, results of infertility treatment have improved considerably, including treatment to overcome ovulation disorders. Despite this, many decisionmakers in health care still consider assisted reproduction to be both expensive and exclusive. However, the fact that limited resources are coupled with unlimited demand for health care means that decisions have to be made regarding the allocation of scarce resources across competing interventions. In this setting, it is important to compare these interventions in the same unit, and the contingent valuation method could be a useful tool for that. In addition, the contingent valuation method does not capture only health-related benefits to the potential recipients of the treatment, as cost-utility analysis, but also includes other aspects of utility and disutility associated with treatment. Indeed, in our study, WTP to have normal cycles of ovulation incorporated other elements than only to increase the probability of having a child, but also psychological outcomes and non-health outcomes. ${ }^{24,28}$ Given that the principal benefits of fertility treatments are not health related, assessment of WTP appears to be the most appropriate approach, allowing costs and benefits to be considered in monetary terms.

Another important point to discuss is that choice in health care funding should reflect the views of the society as a whole. As a consequence, it is important not only to consider the views of the patients but also the views of the general population, especially when we consider public funding. Moreover, as Wagstaff and van Doorslaer ${ }^{29}$ mentioned, fertility treatments like IVF can have a big impact on recipients' ability to flourish as human beings, and it is likely that people consider that these treatments should be available to a majority to build a healthy society. To consider this, in our study, we thus decided to interview the general population. Despite not distinguishing the different reasons why respondents gave a positive WTP, altruism is frequently described to be a significant component of WTP estimates, ${ }^{30,31}$ and it is very likely to be present in our estimates.

\section{Conclusion}

Results associated to our dummy paper showed that there is no evidence of sample frame bias or avidity bias across the two modes (paper and Internet) that cannot be controlled in Probit estimates, which is certainly good news for contingent valuation research. Moreover, results showed that the WTP of women aged 18-45 years to receive medical treatment against infertility in cases where they will be affected by ovulation disorders is very high in Quebec. Given an average maximum WTP of $4,805 \mathrm{CAD}$, this result is largely over the amount of 158-473 CAD needed to get a drug treatment over 6 months (eg, clomiphene citrate); and this result is even higher than the amount actually paid by the Régie de l'assurance maladie du Québec for one cycle of IVF $(4,600$ CAD in 2012) with a maximum of three cycles reimbursed. However, as there was no real payment in our experiment, it should be considered that our study overstated the real economic value of such a treatment. As a consequence, like the NOAA panel, ${ }^{13}$ we recommended that hypothetical bid be deflated using a "divide by 2 " rule. However, dividing our results by two does not change the interest of women in the general population for this type of treatment and thus to have normal cycles of ovulation, considering the vast and persistent difference between WTP and the cost of the treatment.

\section{Acknowledgments}

We acknowledge Christian Bellemare, Renald Lemieux, Suzanne K Bédard, Maryse Berthiaume, and Dr Youssef Ainmelk for their support and helpful comments. We also acknowledge Dr Yves Beaulieu, Dr Jacinthe Dumas, Dr Monique Jobin, Dr Martin Paquet, Dr Pierre Thuot, Dr Bruno Maynard, Dr Dominique Hanna, Dr Jean-Marie Moutquin, Dr Catherine Anku-Bertholet, Dr Guy Waddell, Dr Daniel Thibodeau, Dr Sophie Desindes, and Dr Odette Pinsonneault for giving us their authorization to recruit their patients for this study. Finally, we acknowledge all professionals in the three clinics where patients were recruited.

\section{Contributors}

TGP and JH conceived the study. All authors participated in the study design, planning of analysis and interpretation of the results. TGP was involved in data preparation, statistical analyses, and drafting the article. JH provided statistical expertise and a critical review of the article. CS and JCP provided clinical expertise and helped to draft the article. All authors read and approved the final article. TGP and JCP are members of the FRSQ (Fonds de la recherche en santé du Québec)-funded Centre de recherche du CHUS.

\section{Details of ethics approval}

The study was approved by the Comité d'Éthique à la Recherche sur l'Humain of the CHUS (ref no 08-084). 


\section{Disclosure}

The authors report no conflicts of interest in this work.

\section{References}

1. Chandra A, Martinez GM, Mosher WD, Abma JC, Jones J. Fertility, family planning, and reproductive health of US. women: data from the 2002 national survey of family growth. Vital Health Stat 23. 2005;25:1-160.

2. Zegers-Hochschild F, Adamson GD, de Mouzon J, et al. The International Committee for Monitoring Assisted Reproductive Technology (ICMART) and the World Health Organization (WHO) Revised Glossary on ART Terminology. Hum Reprod. 2009;24(11):2683-2687.

3. The Practice Committee of the American Society for Reproductive Medicine. Optimal evaluation of the infertile female. Fertil Steril. 2004;82(Suppl 1):S169-S172.

4. Speroff L, Glass R, Kase N. Clinical Gynecologic Endocrinology and Infertility. 5th ed. Baltimore: Williams and Wilkins; 1994.

5. Holzer H, Casper R, Tulandi T. A new era in ovulation induction. Fertil Steril. 2006;85(2):277-284.

6. Palumbo A, De La Fuente P, Rodríguez M, et al. Willingness to pay and conjoint analysis to determine women's preferences for ovarian stimulating hormones in the treatment of infertility in Spain. Hum Reprod. 2011;26(7):1790-1798.

7. Mitchell RC, Carson RT. Using Surveys to Value Public Goods: the contingent valuation method. Washington, DC: Resources for the Future; 1989.

8. Carson RT, Hanemann MW. Contingent valuation. In: Maler, KG, Vincent JR, editors. Handbook of Environmental Economics, volume 2 (chapter 17). New York: Elsevier/North-Holland; 2005.

9. Alberini A, Kahn JR. Handbook on Contingent Valuation. Northampton, MA: Edward Elgar; 2006.

10. Whynes DK, Frew E, Wolstenholme JL. A comparison of two methods for eliciting contingent valuations of colorectal cancer screening. $J$ Health Econ. 2003;22:555-574.

11. Yasunaga H. Who wants cancer screening with PET? A contingent valuation survey in Japan. Eur J Radiol. 2009;70(1):190-194.

12. Borghi J, Jan S. Measuring the benefits of health promotion programmes: application of the contingent valuation method. Health Policy. 2008;87(2):235-248.

13. Arrow K, Solow R, Portney PR, Leamer EE, Radner R, Schuman H. Report of the NOAA Panel on contingent valuation. Federal Register. 1993;58:4601-4614. Available from: http://www.darrp.noaa.gov/ library/pdf/cvblue.pdf. Accessed September 10, 2014.

14. Ethier RG, Poe GL, Schulze WD, Clark J. A comparison of hypothetical phone and mail contingent valuation responses for green-pricing electricity programs. Land Econ. 2000;76(1):54-67.
15. Maguire KB. Does mode matter? A comparison of telephone, mail, and in-person treatments in contingent valuation surveys. $J$ Environ Manage. 2009;90:3528-3533.

16. Watson V, Ryan M. Exploring preference anomalies in double bounded contingent valuation. J Health Econ. 2007;26:463-482.

17. Haab TC, McConnell KE. Valuing Environmental and Natural Resources: the econometrics of non-market valuation. Northampton, MA: Edward Elgar; 2002.

18. Whitehead JC. A practitioner's primer on the contingent valuation method. In: Alberini A, Kahn JR, editors. Handbook on Contingent Valuation. Northampton, MA: Edward Elgar; 2006.

19. McFadden D. Conditional logit analysis of qualitative choice behavior. In: Zarembka P. Frontiers in Econometrics. New York: Academic Press; 1974.

20. Hanemann W. Welfare evaluations in contingent valuation experiments with discrete responses. Am J Agric Econom. 1984;67(3):332-341.

21. Granberg M, Wikland M, Nilsson L, Hamberger L. Couples' willingness to pay for IVF/ET. Acta Obstet Gynecol Scand. 1995;74:199-202.

22. Neumann PJ, Johannesson M. The willingness to pay for in vitro fertilization: a pilot study using contingent valuation. Med Care. 1994;32(7):686-699.

23. Ryan M. Should government fund assisted reproductive techniques? A study using willingness to pay. Appl Econ. 1997;29(7):841-849.

24. Ryan M. Valuing psychological factors in the provision of assisted reproductive techniques using the economic instrument of willingness to pay. J Econ Psychol. 1998;19:179-204.

25. Homburg R. Clomiphene citrate - end of an era? A mini-review. Hum Reprod. 2005;20(8):2043-2051.

26. Beattie J, Covey J, Dolan P, et al. On the contingent valuation of safety and the safety of contingent valuation: part 1-caveat investigator. J Risk Uncertain. 1998;17(1):5-26.

27. Cookson R. Willingness to pay methods in health care: a sceptical view. Health Econ. 2003;12:891-894

28. Becker G. The Elusive Embryo: how women and men approach new reproductive technologies. Berkeley, CA: University of California Press; 2000.

29. Wagstaff A, van Doorslaer E. Equity in health care finance and delivery. In: Culyer AJ, Newhouse JP, editors. Handbook of Health Economics, Vol. 1B. North Holland: Elsevier; 2000:1803-1862.

30. Onwujekwe O, Chima R, Shu E, Nwagbo D, Akpala C, Okonkwo P. Altruistic willingness to pay in community-based sales of insecticidetreated nets exists in Nigeria. Soc Sci Med. 2002;54(4):519-527.

31. Lee SJ, Chung HK. Analyzing altruistic motivations in public library valuation using contingent valuation method. Libr Inf Sci Res. 2012; 34(1):72-78. 


\section{Supplementary material}

Table SI Example of contingent valuation questions

Next question is hypothetical and there is no correct or wrong answer.

Before answering, please take the time to consider that to pay for a drug treatment for ovulation induction leads to a reduction in the amount of money available to pay for other goods and services (e.g. hobbies, clothes, travelling, etc.).

Assuming that you cannot have any more ovulations and you have to pay from your own pocket the cost of drug treatment for ovulation again, would you be willing to pay I,000 Canadian dollars?

$\square$ Yes $\square$ No $\square$ I do not know

Are you sure of your answer?

$\square$ Not very sure $\square$ Not sure $\square$ More or less sure $\square$ Sure $\square$ Very sure

\section{Publish your work in this journal}

Patient Preference and Adherence is an international, peer-reviewed, open access journal that focuses on the growing importance of patient preference and adherence throughout the therapeutic continuum. Patient satisfaction, acceptability, quality of life, compliance, persistence and their role in developing new therapeutic modalities and compounds to optimize clinical outcomes for existing disease states are major areas of interest for the journal. This journal has been accepted for indexing on PubMed Central. The manuscript management system is completely online and includes a very quick and fair peer-review system, which is all easy to use. Visit http://www. dovepress.com/testimonials.php to read real quotes from published authors.

Submit your manuscript here: http://www.dovepress.com/patient-preference-and-adherence-journal 